Thorax (1957), 12, 329.

\title{
A CRITICAL EXAMINATION OF THE ROLE OF SURGERY IN THE TREATMENT OF PRIMARY PULMONARY TUBERCULOSIS IN CHILDREN
}

\author{
BY \\ J. K. CAMERON, J. D. HAY, AND L. J. TEMPLE \\ From Leasowe Children's Hospital and the Liverpool Regional Thoracic Centre
}

(RECEIVED FOR PUBLICATION JULY 19, 1957)

In recent years surgery has played an increasingly large part in the treatment of primary tuberculosis of the lungs in children. We have been impressed by this increasing frequency, and also by descriptions of gross pathological changes in mediastinal glands and lung parenchyma found at thoracotomy (Thomas, 1952 ; Huish, 1956). In consequence we have been concerned lest the treatment, or lack of treatment, of our own patients might be resulting in unnecessary residual damage to lung structure, or even in the development in some cases of the adult forms of pulmonary tuberculosis. We therefore decided to analyse and follow up all children admitted to Leasowe Children's Hospital with primary tuberculosis during the years 1949 to 1955 , and also to study by bronchoscopy and/or bronchography those showing features which might conceivably be regarded as indicating the need for surgical intervention, either early or late.

We report the results of this investigation and of such surgical treatment as we considered to be advisable; and we discuss the role of surgery in the treatment of primary tuberculosis in childhood.

\section{MATERIAL}

Four hundred and nine children have been reviewed. Of these 48 were specially investigated. As a result of investigations, five only were treated surgically. The ages in the whole series varied from infancy to 16 years. They were referred for admission to the hospital principally by the paediatricians and chest physicians of Merseyside, by whom they were also followed up after discharge.

They are a selected group, in that many of the mildest cases were probably not referred, and the rapidly fatal cases never reached us, although a considerable proportion of the children admitted were severely ill.

\section{TREATMENT}

The hospital is of an open-air type, situated by the sea and in a bracing climate. Treatment for most patients has been on general lines only, beginning with a period of bed-rest, usually short, and proceeding to full activity in the absence of signs of active disease. The use of antibiotic drugs has been irregular, as our policy has been to continue wherever possible the wishes of the referring consultant. We have initiated antibiotic treatment in all infants under 2 years (Debré, 1951 ; Todd, 1953) and also in a few children, most of whom were being prepared for surgery. Approximately $10 \%$ of all our cases received antibiotics at some stage. We noted no significant difference between those treated with and those treated without antibiotics, nor did segmental lesions appear to resolve more rapidly under their influence.

\section{General Analysis of Series}

Our findings are similar to those of Bentley and others and of Walker (Bentley, Grzybowski, and Benjamin, 1954; Walker, 1955), and are only described briefly and by making full use of charts. We consider that this analysis is a necessary background to our special investigations. In view of the extensive bibliographies compiled by Bentley and Walker a further review of the literature is unnecessary at this stage.

Table I shows our analysis of the patients when admitted. The majority of cases were recognized on admission as assignable to one or other group. About $5 \%$ of the patients in group 2 had large gland masses and we considered putting them into a separate category, but decided against this as no other distinctive feature appeared.

In common with others, we employ the term segmental lesion to describe a radiological appearance in which lung involvement, whether it re- 
TABLE I

CLASSIFICATION ON ADMISSION OF 409 CASES OF PRIMARY PULMONARY TUBERCULOSIS

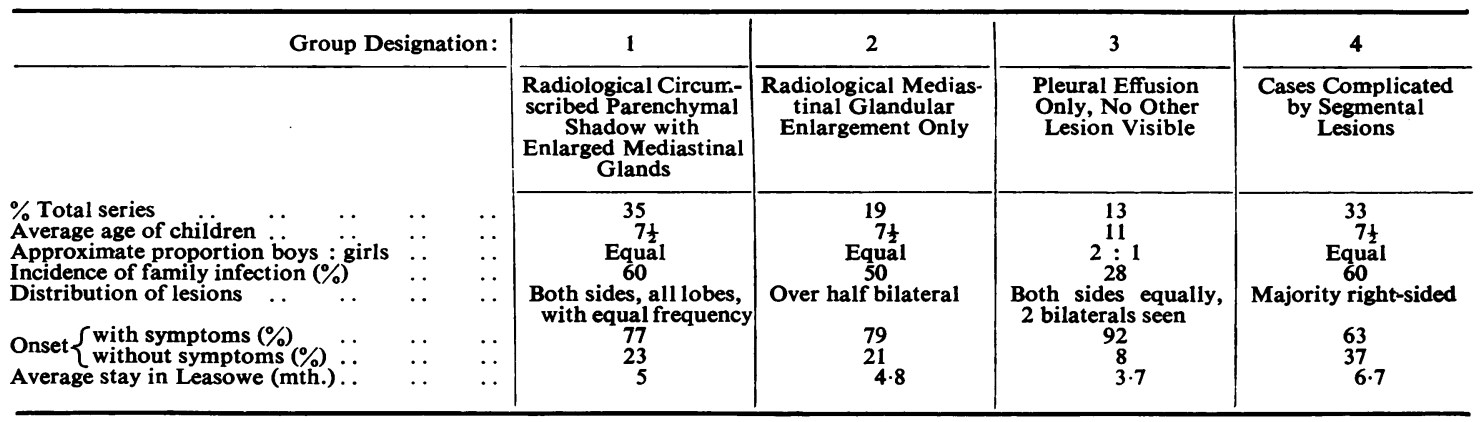

sembles collapse or consolidation, is associated with pressure on the hilar bronchi, but we do not believe that the lesion is actually limited by the bounds of a bronchopulmonary segment. We regard such segmental lesions as a complication of primary disease. The uncomplicated cases in this series have given rise to no anxiety, having rapidly become and remained well during our period of observation. We have, on the other hand, been concerned with the segmental lesions, and 48 of the more persistent of these form the subject of our special investigation.

Apart from segmental lesions other complications in the lungs have been: (a) miliary changes in the lung fields, observed in each case in the early films and clearing completely (10 cases); (b) cavitating primary lesions which also all cleared (six cases) (Fig. 1); (c) adult type of chronic pulmonary tuberculosis developing later, which is separately analysed below (12 cases).

Extrapulmonary complications were: (a) skeletal lesions, all mild (seven cases); (b) tuberculous meningitis in two infants aged 11 and 14 months who died, these being the only fatal cases in the entire series.

The incidence of the adult type of pulmonary tuberculosis is summarized in Tables II and III. The average time between primary infection and the onset of adult-type disease is slightly over two years. The number of cases of reactivation does not increase with the passage of time within the main follow-up period of eight years. In the majority, this sequel follows classical primary disease of group 1 type, and has not occurred in a single case of primary disease complicated by a segmental lesion. In five out of the nine cases

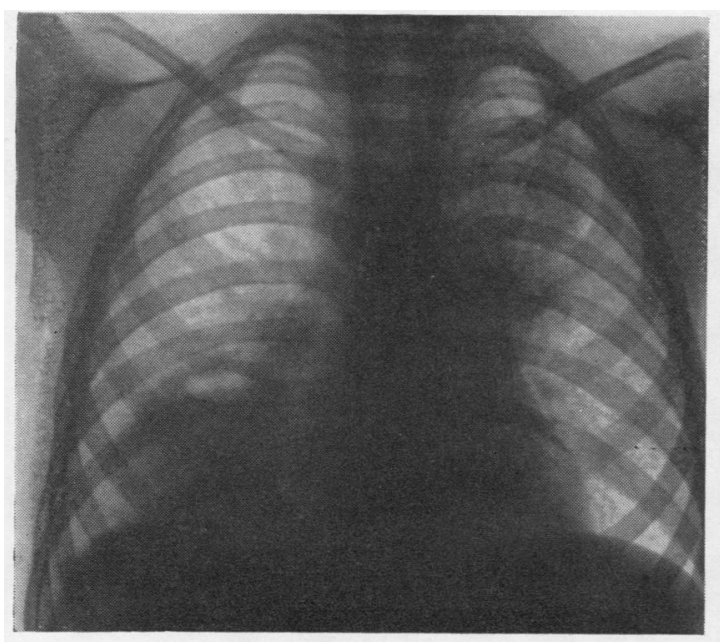

(a)

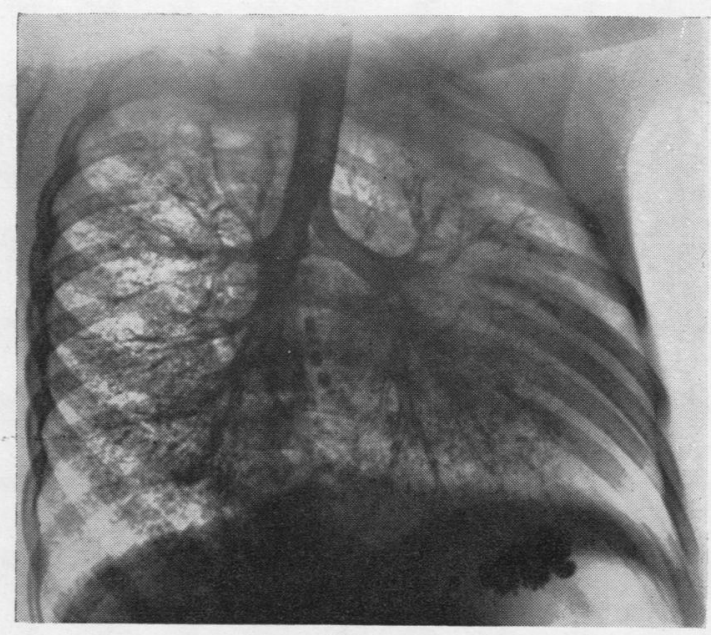

(b)

FIG 1.-(a) Film of child aged 2 on admission showing bilateral segmental lesions-cavitated on right; (b) 14 months later-complete radiological clearing with minor bronchiectasis of the left upper lobe. 
TABLE II

INCIDENCE OF CHRONIC DISEASE OF ADULT TYPE

\begin{tabular}{|c|c|c|c|c|}
\hline $\begin{array}{l}\text { Patients' } \\
\text { Initials }\end{array}$ & $\begin{array}{l}\text { Age at } \\
\text { Time of } \\
\text { Primary } \\
\text { Infection } \\
\text { (Years) }\end{array}$ & $\begin{array}{c}\text { Year of } \\
\text { Primary } \\
\text { Infection }\end{array}$ & $\begin{array}{c}\text { Time } \\
\text { between } \\
\text { Primary } \\
\text { Infection } \\
\text { and Re- } \\
\text { activation } \\
\text { (Years) }\end{array}$ & $\begin{array}{c}\text { Type of } \\
\text { Primary Infection }\end{array}$ \\
\hline M.L. & 11 & 1950 & 5 & Primary complex. \\
\hline $\begin{array}{l}\text { T.C. } \\
\text { J.L. }\end{array}$ & $\begin{array}{l}14 \\
14\end{array}$ & $\begin{array}{l}1950 \\
1950\end{array}$ & $\begin{array}{l}2 \\
1 \frac{1}{2}\end{array}$ & $\begin{array}{l}\text { Pleurisy. Group } 3 \\
\text { Primary complex. } \\
\text { Group } 1\end{array}$ \\
\hline D.B. & 7 & 1951 & 5 & $\begin{array}{l}\text { Gland enlargement only. } \\
\text { Group } 2\end{array}$ \\
\hline $\begin{array}{l}\text { B.S. } \\
\text { D.M. }\end{array}$ & $\begin{array}{l}15 \\
11\end{array}$ & $\begin{array}{l}1952 \\
1952\end{array}$ & $\frac{2}{2}$ & $\begin{array}{l}\text { Pleurisy. Group } 3 \\
\text { Primary complex. } \\
\text { Group } 1\end{array}$ \\
\hline R.R. & 12 & 1952 & 2 & $\begin{array}{l}\text { Primary complex. } \\
\text { Group } 1\end{array}$ \\
\hline C.B. & 14 & 1953 & 1 & $\begin{array}{l}\text { Gland enlargement only. } \\
\text { Group } 2\end{array}$ \\
\hline B.L. & 13 & 1953 & 2 & $\begin{array}{l}\text { Primary complex. } \\
\text { Group } 1\end{array}$ \\
\hline W.C. & 15 & 1953 & 2 & $\begin{array}{l}\text { Primary complex. } \\
\text { Group } 1\end{array}$ \\
\hline L.F. & 14 & 1955 & 0 & $\begin{array}{l}\text { Primary complex. } \\
\text { Group } 1\end{array}$ \\
\hline J.R. & 15 & 1955 & 1 & $\begin{array}{l}\text { Primary complex. } \\
\text { Group } 1\end{array}$ \\
\hline
\end{tabular}

TABLE III

\begin{tabular}{|c|c|c|c|c|c|c|c|c|c|c|}
\hline \multirow{2}{*}{\multicolumn{2}{|c|}{$\begin{array}{c}\begin{array}{c}\text { Primary } \\
\text { Disease } \\
\text { Admissions }\end{array} \\
\text { Year Total }\end{array}$}} & \multicolumn{9}{|c|}{$\begin{array}{l}\text { Number of Instances of Adult-type Disease } \\
\text { and Year of Occurrence }\end{array}$} \\
\hline & & 1949 & 1950 & 1951 & 1952 & 1953 & 1954 & 1955 & |1956 & 1957 \\
\hline 1949 & 16 & & & & & & & & & \\
\hline 1950 & 43 & & & & 2 & & & 1 & & \\
\hline 1951 & 53 & & & & & & & & 1 & \\
\hline 1952 & 73 & & & & & & 3 & & 2 yea & \\
\hline 1953 & 93 & & & & & & 1 & 2 & $\operatorname{lin}$ & it \\
\hline 1954 & 75 & & & & & & & & & \\
\hline 1955 & 45 & & & & & & & 1 & 1 & \\
\hline
\end{tabular}

in which information is complete the reactivation of disease occurred at or near the site of the primary lesion. There is no evidence to show that adult-type disease has so far followed a segmental lesion either in direct relation to it or elsewhere in the lungs, but the short period of followup does not preclude the possibility of this occurring later. Concern at this possibility has been our strongest motive for undertaking the investigation of cases with segmental lesions which is described later in this paper.

The results of the follow-up of this series of 409 cases are given in Table IV. The 7\% failure in follow-up is due to the accident of geography and we therefore consider that its selection is random. The follow-up is based on reports from many different physicians, which adds emphasis
TABLE IV

FOLLOW-UP

\begin{tabular}{|c|c|c|c|c|c|}
\hline \multicolumn{2}{|c|}{$\begin{array}{l}\text { No. and Description of } \\
\text { Group, with Totals in Each : }\end{array}$} & $\begin{array}{c}1 \\
\text { Both } \\
\text { Lung and } \\
\text { Gland } \\
\text { Lesion } \\
\text { Visible } \\
\text { (145 } \\
\text { Cases) }\end{array}$ & $\begin{array}{c}2 \\
\text { Glandular } \\
\text { Enlarge- } \\
\text { ment } \\
\text { Only } \\
\text { Visible } \\
\text { (76 } \\
\text { Cases) }\end{array}$ & $\begin{array}{l}\text { 3 } \\
\text { Primary } \\
\text { Pleural } \\
\text { Effusion } \\
\text { (53 } \\
\text { Cases) }\end{array}$ & $\begin{array}{l}4 \\
\text { Compli- } \\
\text { cated by } \\
\text { Segmen- } \\
\text { tal } \\
\text { Lesion } \\
\text { (135 } \\
\text { Cases) }\end{array}$ \\
\hline \multicolumn{2}{|c|}{ Followed up $(\%) \quad \ldots \quad \ldots$} & 98 & 86 & 94 & 93 \\
\hline \multirow{3}{*}{$\begin{array}{c}X \text {-ray } \\
\text { Reports }\end{array}$} & \multirow{2}{*}{$\begin{array}{l}\text { Normal appear- } \\
\text { ance }(\%) \\
\text { Residual changes, } \\
\text { but no evidence } \\
\text { of active disease } \\
(\%) \quad \ldots\end{array}$} & 76 & 70 & 72 & 46 \\
\hline & & 19 & $14 \cdot 5$ & 22 & 47 \\
\hline & $\begin{array}{ll}\text { Appearance } & \text { of } \\
\text { adult forms } & \text { of } \\
\text { disease }(\%) & \ldots\end{array}$ & 2 & 0.5 & 0.5 & 0 \\
\hline \multicolumn{2}{|c|}{ Deaths $(\%)$} & & $\begin{array}{c}0.5 \\
\text { gitis) }\end{array}$ & & \\
\hline \multicolumn{2}{|c|}{$\begin{array}{c}\text { Average period under ob- } \\
\text { servation (mth.) } \ldots\end{array}$} & 39 & 42 & 36 & 38 \\
\hline
\end{tabular}

in particular to the finding of a high percentage $(47 \%)$ of children whose chest films following a segmental lesion showed some persisting abnormality.

\section{Results of InVestigations and Treatment of SEgmental Lesions}

A total of 48 children with segmental lesions, bilateral in four, have been investigated by means of bronchoscopy and/or bronchography between January, 1953, and December, 1955. These patients were selected for investigation with a view to determining the advisability of surgical treatment because progress on routine medical measures was unsatisfactory or there appeared to be residual lung damage at the conclusion of treatment. Where necessary, investigations were repeated in order to note progress, and, in some, bronchographic abnormalities were seen when the straight film had become normal. Before 1953 we were less aware of the necessity for bronchographic examination and doubtless many abnormalities might well have been missed. Further investigation of these 48 patients revealed not surprisingly a higher incidence of permanent damage than demonstrated in the pre-1953 patients.

In all, 51 bronchograms were obtained in 42 patients.

At the conclusion of the investigation only 11 of the children had completely normal chest films and bronchograms, while 37 showed some abnormality. 


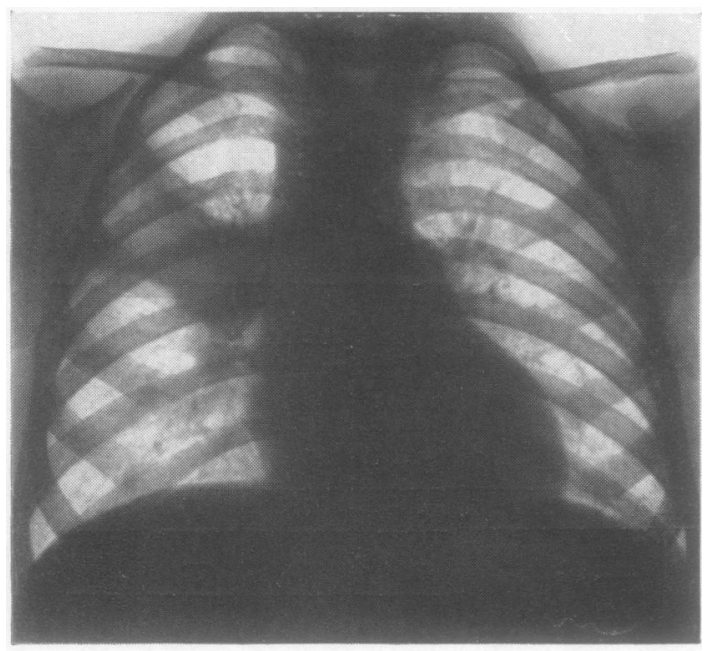

FIG. $2 a$

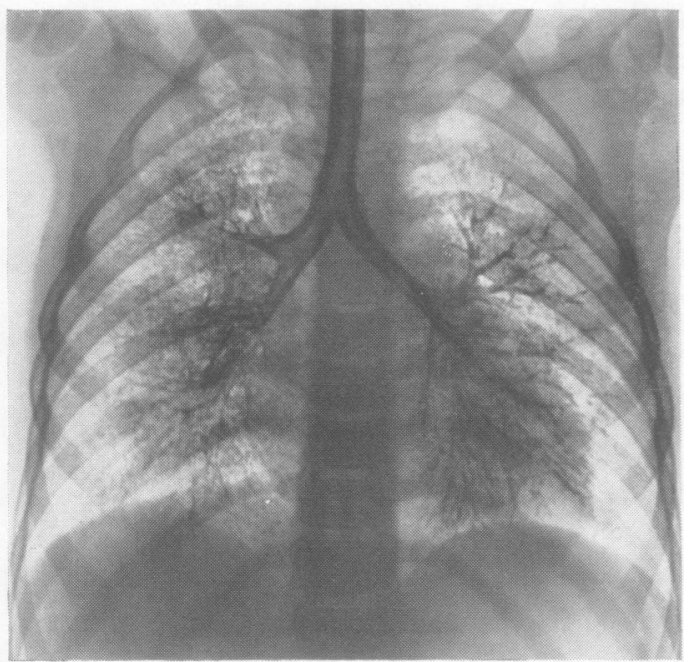

Fig. 2'
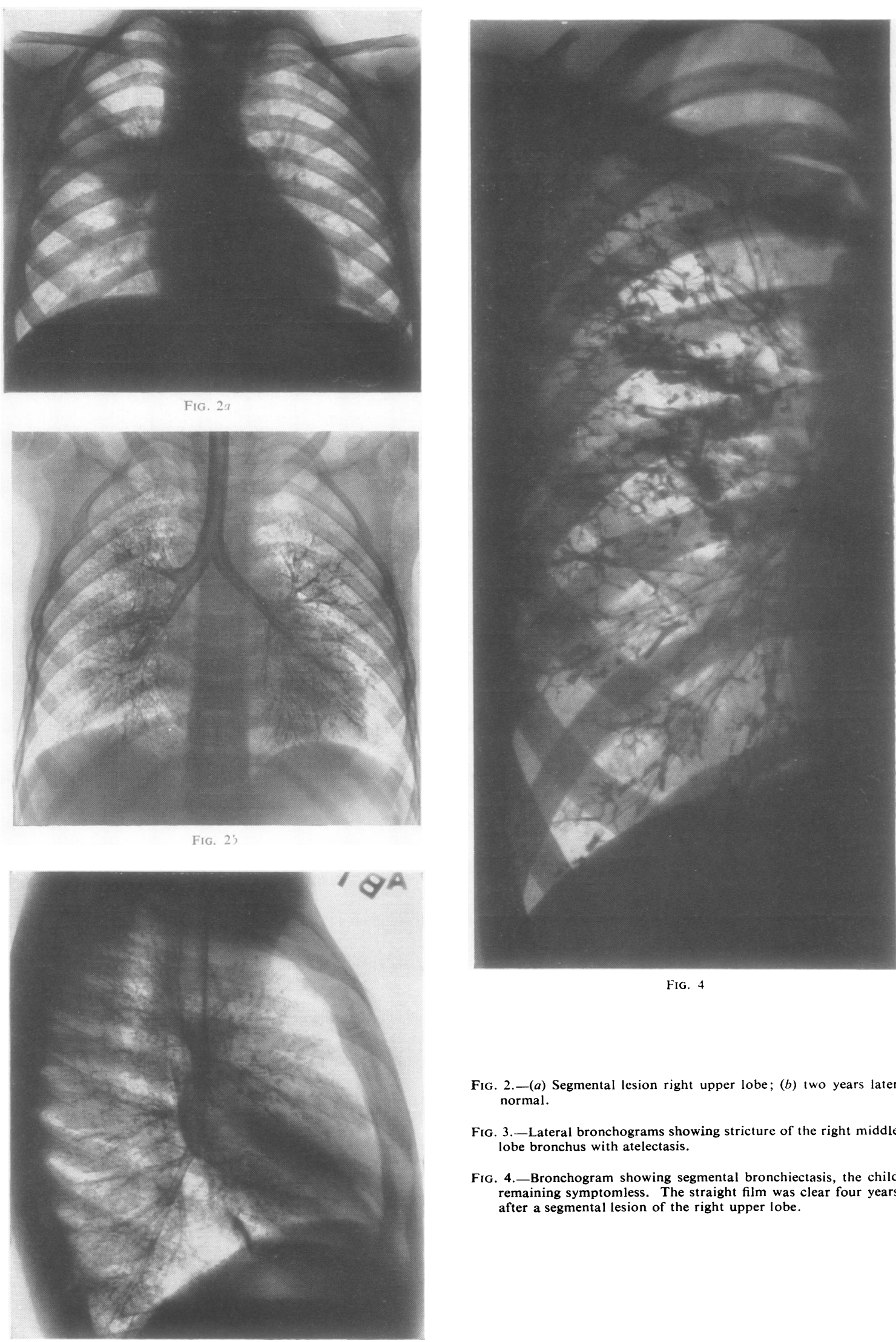

FIG. 4

Fig. 2.-(a) Segmental lesion right upper lobe; $(b)$ two years later normal.

FIG. 3.-Lateral bronchograms showing stricture of the right middle lobe bronchus with atelectasis.

FIG. 4.-Bronchogram showing segmental bronchiectasis, the child remaining symptomless. The straight film was clear four years after a segmental lesion of the right upper lobe. 
Nine had areas of fibrosis or pleural thickening on the straight film which were not considered to be of clinical importance as their bronchograms were normal (Fig. 2).

Two had areas of punctate calcification scattered in the parenchyma but with normal bronchograms.

In five, bronchial strictures were seen in the bronchograms, four of the right middle lobe bronchus, and one in an upper lobe segment (Fig. 3).

In nine, bronchograms revealed minor areas of tubular bronchiectasis, usually in a single segment of an upper lobe (Fig. 4).

Six showed areas of atelectasis in a straight film or a segmental filling defect on bronchography.

One child has an area of fibrosis only and a normal bronchogram but is kept in a separate category because of intermittent signs of toxicity, the cause of which is obscure, but is not, we believe, tuberculous in origin.

In none of these 32 patients do we consider that major surgery is justified at present.

Five patients have undergone resection, four for the removal of both right middle and lower lobes which were bronchiectatic, and one for the removal of the left upper lobe, the site of a lobar bronchial occlusion.

Bronchoscopy was carried out 39 times in 27 patients. The contents of caseous glands was aspirated whenever possible. Initial bronchoscopy showed granulations in 12 patients, stricture in one, glandular pressure in two, and normal appearances in the remaining 12 . Of the 12 with granulations, collapse was persistent in four, and the right middle and right lower lobes were resected in each case as already mentioned (Fig. 5).

In five cases subsequent investigation showed that the lung cleared after repeated bronchoscopic aspiration, leaving no residual collapse or bronchiectasis, but in the remaining three there was some persistent collapse and bronchiectasis in spite of clearing the granulations.

The single stricture has persisted without symptoms, and was the only stricture of the five demonstrated bronchographically that could be seen with the bronchoscope. Of the two patients with glandular pressure, resection was carried out in one, and in the other, in whom atelectasis and bronchiectasis persisted, surgery was refused.

It is inferred from the results of bronchoscopy that early aspiration of the bronchi in patients in whom the gland has ruptured may result in complete radiological clearing of the peripheral lesion,

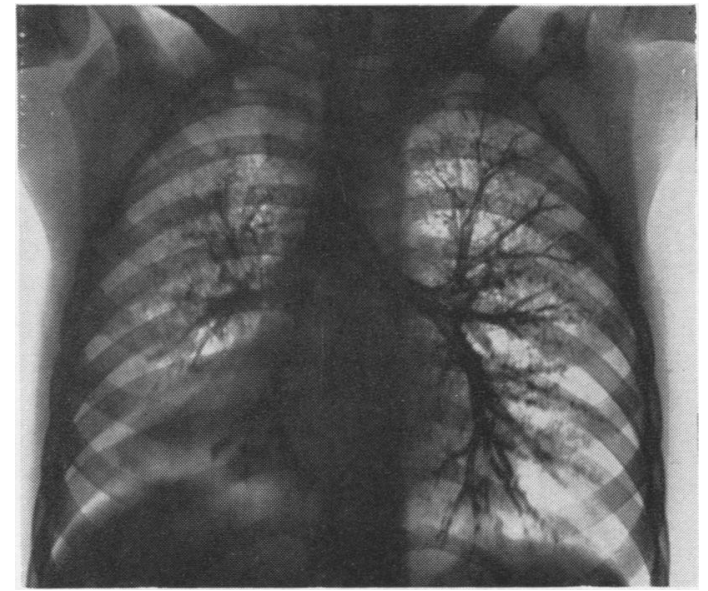

FIG. 5.-A child with persisting collapse of right middle and lower lobes. Bronchograms show intermediate bronchus almost occluded by granulations, with distal bronchiectasis. Middle and lower lobes subsequently resected. Bronchoscopy had not been undertaken until collapse had been present for three months.

and that this method of treatment should be more freely used (Fig. 6) (Görgényi-Göttche and Kassay, 1947). The four patients whose right middle and right lower lobes were resected were not submitted to bronchoscopy until the condition had been present for three months to three years. In subsequent cases bronchoscopy has been resorted to earlier with improved results. Bronchoscopy was not often of value in upper lobe lesions.

The resections were carried out because of the damage to lung structure rather than the suspicion of persisting tuberculous infection. Of the resected specimens, two showed tuberculosis in the lung parenchyma, and three bronchiectasis and fibrosis only, with, in one, a caseous focus in a hilar gland. In the three specimens in which some evidence of tuberculosis was found, healing tendencies were seen. We thought that in each case the resection was justified by the extent of the permanent lung damage, but not by the persistence of tuberculous infection. It seemed probable that in time the tuberculous infection would have become quiescent in each case, but that the bronchiectasis and collapse, being irreversible, had merited removal. It was noted at operation that the hilar structures were matted and fibrosed so that individual vessels were dissected with difficulty and danger. A similar condition has been noted in adults at operation for bronchial stricture, even when there has been no evidence of active tuberculosis. All five resected cases had a covering course of anti-tuberculosis drugs started approximately six weeks before operation and maintained 


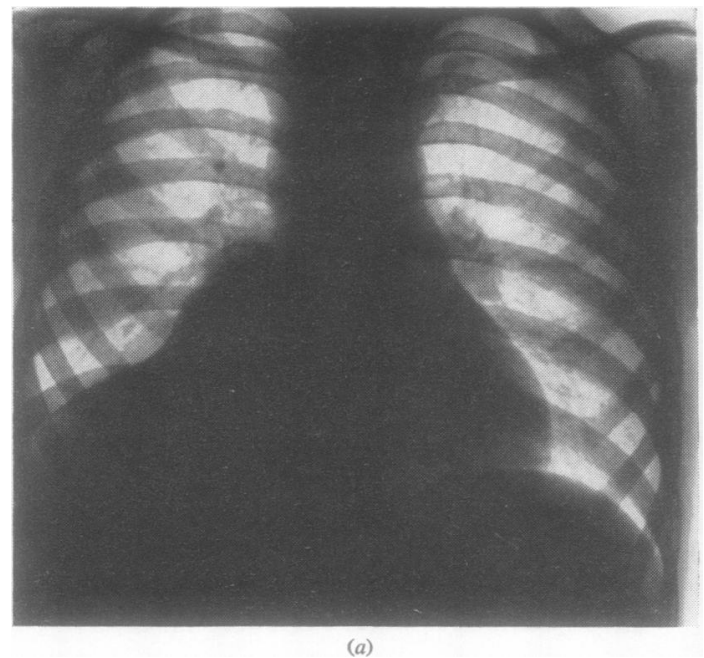

Fig. 6.-(a) Collapse of right middle and lower lobes; (b) bronchogram showing complete re-expansion after repeated bronchoscopic aspiration. Some granulations still project into the bronchus (these were subsequently aspirated). Minor bronchiectasis persists, but most of the lung is normal.

for at least three months afterwards. In one, antibiotics had been given for two years before admission for previous tuberculosis of bones and testis.

\section{DISCUSSION}

In considering the results of treatment in this group of 48 patients, we are disappointed at the proportion who have some residual lung damage. The object of our investigation has been to ascertain how serious this threat is to the future wellbeing of the patient, and to what extent surgery could have prevented it, or could at this stage still prevent further trouble.

From the point of view of possible prophylaxis, surgery could have played little part in preventing the onset of the segmental lesions, since in 45 out of the 48 patients this complication was fully developed on admission. Indeed, of all the children in this series of 409 who did not have a segmental lesion on admission only seven subsequently developed one. It could be argued that in some patients with uncomplicated primary tuberculosis who are making satisfactory progress there may be enlarged and caseating hilar glands the removal of which would prevent the development of a segmental lesion. In our experience such cases have been difficult or impossible to recognize, so that prophylactic thoracotomy to be effective would have to be undertaken in all children with uncomplicated primary disease. In this series this would have meant more than 200 thoracotomies

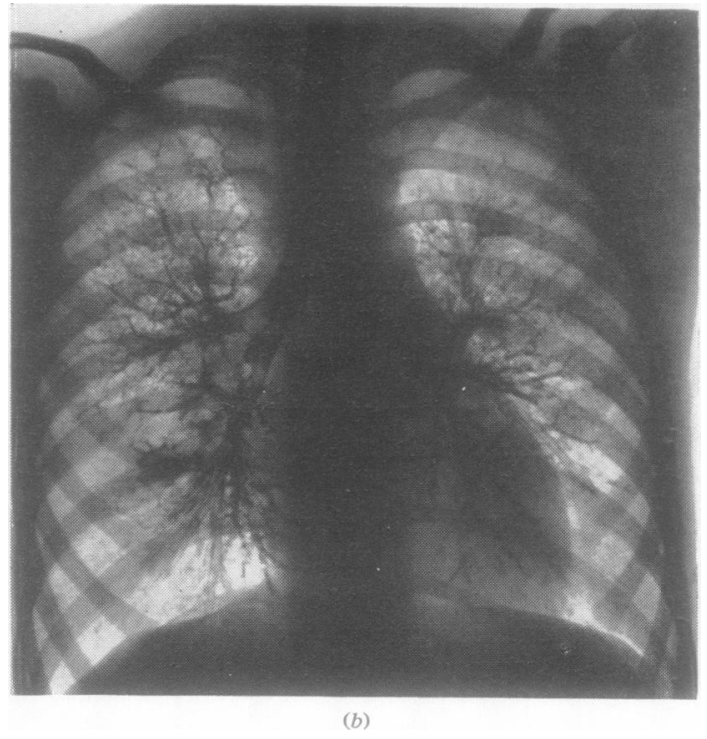

in order to prevent the subsequent development of seven segmental lesions, to our minds an unjustifiable policy, particularly since the segmental lesions which have developed have proved to be relatively benign.

In cases of respiratory distress due to pressure of caseous gland masses, immediate surgical intervention may be required (Thomas, 1952 ; Chesterman, 1957). Fortunately there has been no instance of this in our series.

If surgery is undertaken after the development of the segmental lesion, both the glands and the affected area of lung must be removed in every case ; for, while Seal (Seal and Thomas, 1956) has pointed out that histological examination of some segments so removed shows pathological changes that are reversible, this could not be recognized at thoracotomy before removal of the diseased segment. We have to ask if the disadvantages and dangers of such a radical procedure, undertaken in the early stages of the disease before the development of signs of permanent lung damage, are less than those to which the untreated patient remains exposed. In answering this question we have to consider first the likelihood of secondary structural lung damage, and secondly the possibility of the development of adult-type tuberculosis. We have attempted to do this by an analysis of the 48 specially investigated patients on the basis of the present condition of their lungs.

With regard to the development of permanent lung damage, the 11 patients who now have normal radiographs and bronchograms would have 
FIG. 7.-Specimen of left lung removed from adult aged 25 showing (A) an old healed primary lesion, and (B) a caseous node between the bronchi in the lung substance. This node was most likely to have been missed during any operation at the time of primary infection. (C) Dissemination to the base has occurred from this caseous node (primary infection unnoticed in this patient).

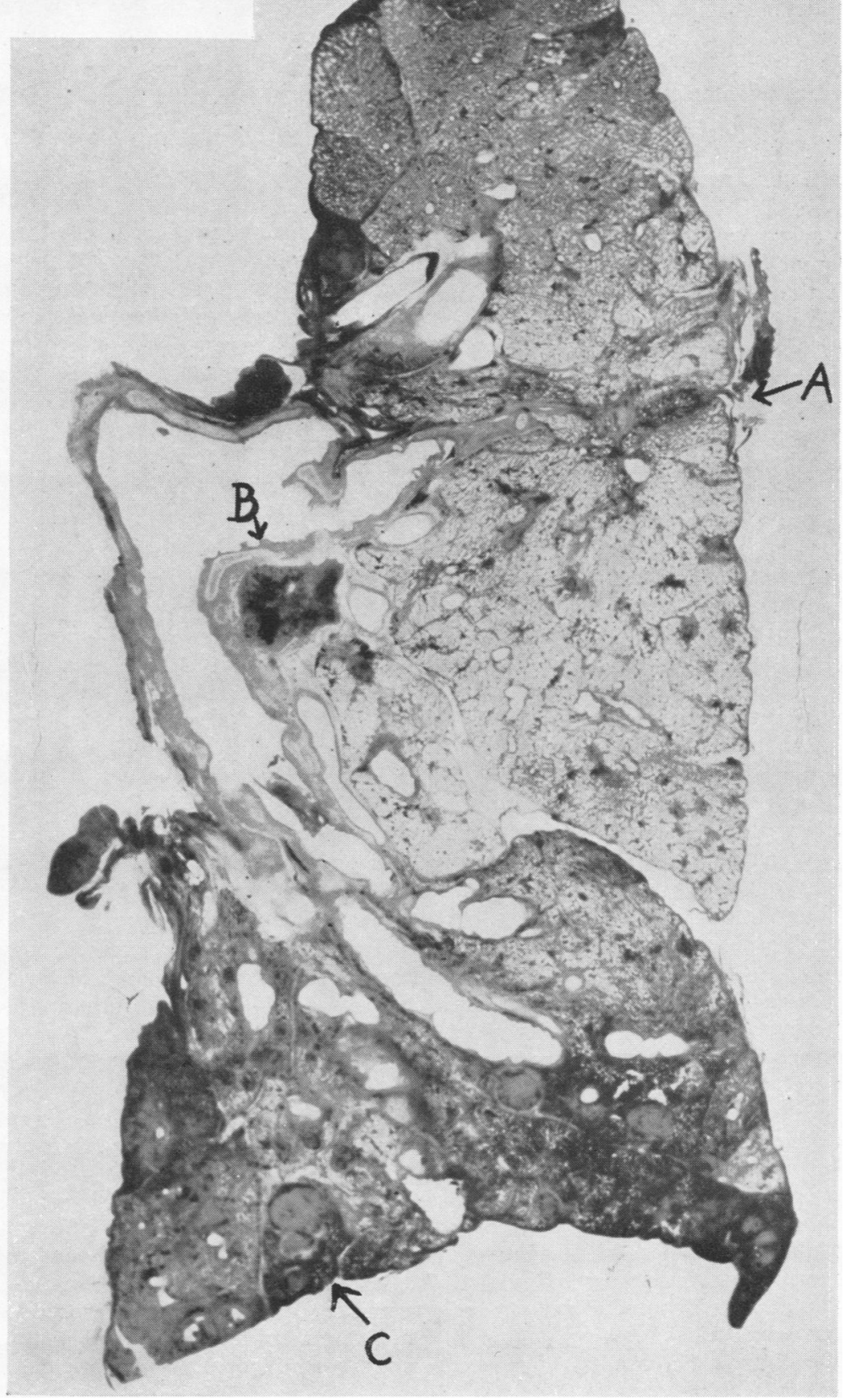


gained nothing from surgery. This is also true of the nine with areas of fibrosis or pleural thickening only and of the two with punctate calcification. The nine with minor bronchiectatic changes and no symptoms are also unlikely to benefit from surgery: such changes are commonly found on routine radiography of adults who are symptomless.

The five children with bronchial stricture and the six with areas of atelectasis or segmental bronchial block may all require surgery in the future. Brock (1950) has described the syndrome of collapsed middle lobe resulting from a primary infection in childhood. Most of these patients do not present with symptoms until middle age, and many remain symptomless throughout life (Fretheim, 1952). We therefore do not feel justified in undertaking surgery in the absence of symptoms. The radiological appearances of these persisting segmental lesions occasionally suggest the possibility of empyema of a blocked bronchus, but this suspicion only arose in one of our patients, which, together with an absence of instances of subsequent "flare-up" in our series as a whole, suggests that our conservative policy is justified. Reference has already been made to those adults operated on for stricture of the bronchus in whom a matted hilum typical of primary infection has been found. Such patients have had the advantage of surgical treatment after the infective process has become quiescent, and not soon after primary infection when some tuberculous activity might still have been present.

In considering the likelihood of these children developing adult forms of pulmonary tuberculosis and the pcssibility that early surgery might prevent this sequel, we have analysed the follow-up of our total series of all groups year by year (Table III). Although the value of such a short follow-up is limited, we consider our findings to be significant. Our analysis shows that the tendency to develop adult-type disease does not increase with the passage of time, as most instances occurred within two years of discharge from hospital. Furthermore, the patients who had segmental lesions seemed less prone to develop chronic pulmonary tuberculosis than those in the other groups: in our series no such case has developed this complication. The inference would appear to be supported by our experience that the matted hilum associated with segmental lesions is rarely seen at operation for pulmonary tuberculosis in adults, in whom a history of primary illness is usually also lacking. This is in contrast to the findings in adults who have the middle-lobe stricture syndrome. Surgical treatment of persistent segmental lesions would probably not play a part in the prevention of the adult type of disease. Its value would seem to be limited both by the difficulty of removing all the infected hilar glands and by the fact that reactivation could occur as readily from an inconspicuous lymph node embedded in the lung substance as from a large hilar gland (Fig. 7).

\section{Summary AND CONCLUSION}

A series of 409 cases of primary lung tuberculosis has been analysed after follow-up of 18 months to eight years. Thirty-three per cent. of these were complicated by segmental lesions, and evidence is produced suggesting that few of the latter are likely to resolve completely. The future dangers which have been stated to threaten children showing a segmental lesion are:

(a) The development of disease of the adult type; our evidence is against this, and the instances of this condition which have occurred arise from previously uncomplicated cases.

(b) Permanent lung damage.

An investigation of 48 of the more severe cases of segmental lesions is described.

Surgery carries hazards, both because of the dangers inherent in dissecting a matted lung hilum and the possibility that the difficulties of such a dissection may lead to the resection of sound lung. It has been reserved for five patients who had severe and irreversible lung damage. We conclude that the place of surgery is in the eradication of grossly damaged areas of lung especially involving middle and lower lobes. It may also be required in cases of pressure by enlarged gland masses with stridor. We have been unable to find any other indication for thoracotomy, and in particular we do not believe that persisting segmental shadows should be removed because of the fear that tuberculosis of adult type will develop from them, either early or late.

Anticipatory surgery would appear to anticipate only the worst possible results of conservative treatment, without offering any compensatory advantage or guarantee against further development of tuberculous infection.

We are impressed with the curative value of the ordered and tranquil life of a children's sanatorium. This is essential during the early period after infection and while activity of the disease persists. It is seldom that results comparable to our series could be obtained in the normal home conditions of most of our patients. 
The additional routine use of antibiotics does not seem to offer any advantage, and we think that even the possibility that we might have prevented the development of adult tuberculosis in some of the $3 \%$ occurrence in our series would not have justified the use of antibiotics for two to three years in over 400 children.

Our experience is that most primary infections in children, even when severe or complicated, will resolve on adequate conservative treatment without recourse to surgery or antibiotics.

We are greatly indebted to the many physicians and the staffs of chest clinics who so patiently helped us again and again with the radiographs and information we required. We particularly would like to thank Dr. Robert Coope for advice both in the investigations and in writing up our results.

The lung section was prepared under part of a research scheme financed by the Research Committee of the United Liverpool Hospitals.

\section{REFERENCES}

Bentley, F. J., Grzybowski, S., and Benjamin, B. (1954). Tuberculosis in Childhood and Adolescence. N.A.P.T., London.

Brock, R. C. (1950). Thorax, 5, 5.

Chesterman, J. T. (1957). Ibid., 12, 159.

Debré, R. (1951). Proc. roy. Soc. Med., 44, 1067.

Fretheim, B. (1952). Thorax, 7, 156.

Görgényi-Göttche, O., and Kassay, D. (1947). Amer. J. Dis. Child., 74, 166.

Huish, D. W. (1956). Thorax, 11, 186.

Seal, R. M. E., and Thomas, D. M. E. (1956). Lancet, 2, 995.

Thomas, D. (1952). Proc. roy. Soc. Med., 45, 743.

Todd, R. M. (1953). Brit. med. J., 1, 1247.

Walker, C. H. M. (1955). Lancet, 1, 218. 